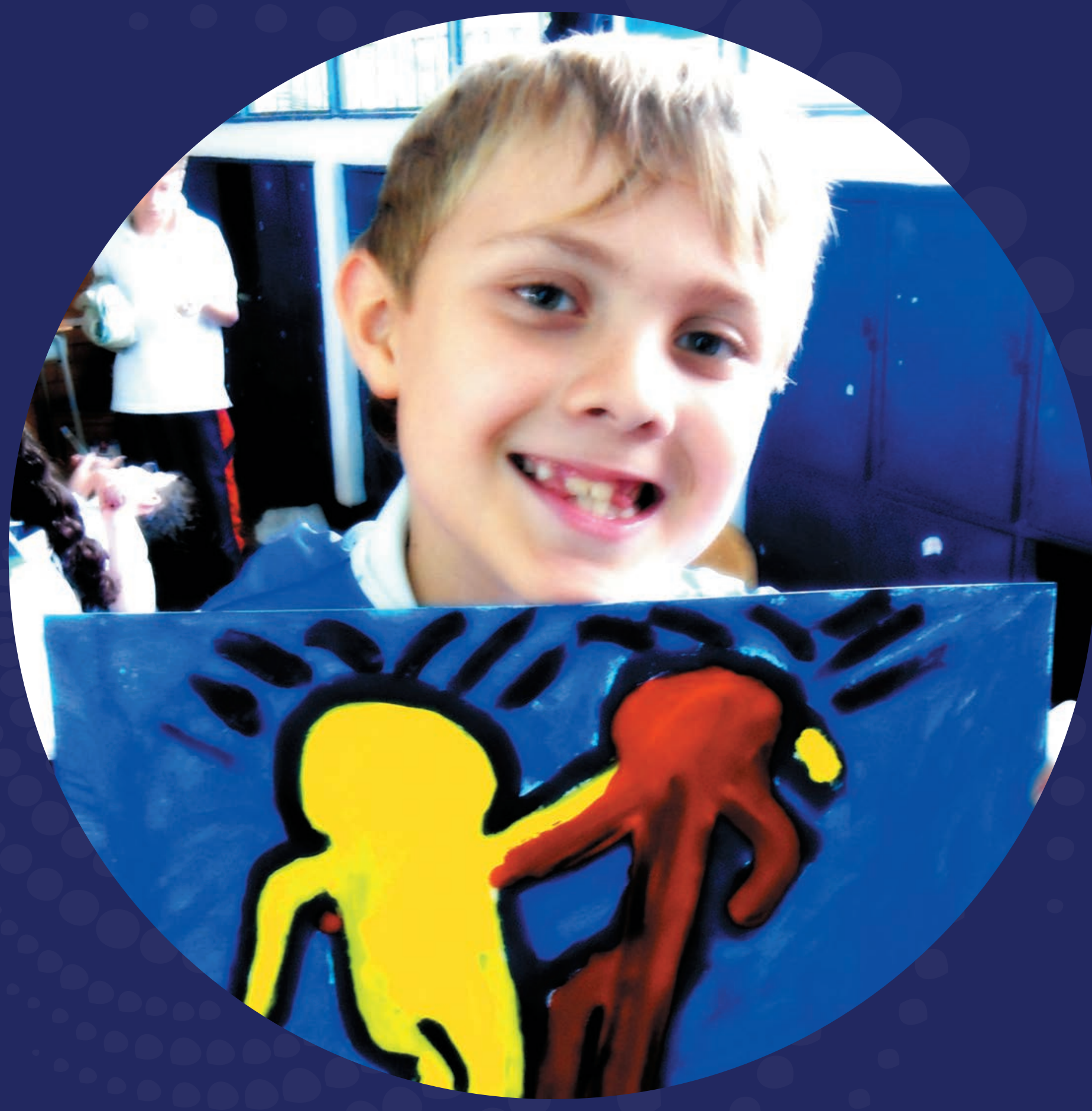

DÍA A DÍA EDUCATIVO: CRÓNICAS 



\title{
LECTURAS DEL ASOMBRO: POÉTICAS DE LA MEMORIA EN CLAVE DE MUJER
}

\author{
Mery Yolanda Sánchez ${ }^{1}$ \\ meryyolanda@gmail.com
}

Cuando escribo lo que hago es un trazo de mi presencia sobre el papel. El ser creador es libre y la poesía a través del símbolo altera la realidad en beneficio de una estética. Tal vez, por eso no tenemos demanda en el mercado de la industria cultural. La buena salud editorial se debe más a los productos que no transforman ni sirven como mediadores para provocar la reflexión.

Somos memoria aún en nuestras expresiones fantásticas. Hacemos poesía desde nosotros, y si acudimos a personajes literarios, estos son parte de seres que hemos conocido y que han quedado codificados en nuestra mente.

Los instrumentos que usa la historiografía, como memoria estatal, son fríos. Necesitamos palpar, tentar lo emocional para reconstruir desde lo orgánico y moldear de mejor manera el barro de nuestra casa. Me refiero a la casa como mi estructura, donde toma asiento la comunidad con la que evoluciono. Hay vacíos cuando se registra la historia que no da prioridad a lo humano. El poeta lee el alma del otro en las entrelíneas del surco de la tierra, se atreve, denuncia,

1 Nació en el Guamo, Tolima en 1956. Ha publicado los libros de poesía "La ciudad que me habita" (1989), "Ritual para las noches" (1997), "Dios sobra, estorba" (2006) y la antología "Un día maíz" (2010 Obra inédita Gradaciones (poema), Último llamado (dramaturgia). Sus poemas, cuentos, comentarios literarios y reseñas de libros han aparecido en diferentes antologías y magazines del país. Obtuvo mención de honor en el concurso El cuentista Inédito del Centro de Estudios Alejo Carpentier en 1987 y en 1994. Fue beneficiada con la Beca Nacional 1998 del Ministerio de Cultura por su proyecto Poesía en Escena (propuesta escénica para la presentación de lecturas de poesía que se realiza en Bogotá desde 1993) Ha orientado talleres de poesía para niños, jóvenes, población de internos en centros carcelarios y Habitantes de la calle. Diseñó y ejecutó para el Comité de Derechos Humanos de la Personería de Bogotá el proyecto Puente Experimento Piloto (el teatro, la danza y la literatura como liberadores de la violencia intrafamiliar). Dirige la Asociación Libre para las Artes -Alartes-, entidad de gestión artística y cultural que realiza producción técnica y logística de eventos masivos y de sala. (1989). cuestiona y convoca a otras lecturas, lejos del relato plano y escueto de los titulares de la prensa oficial.

Las personas y los colectivos acumulan vivencias, así se forma la historia, la que no recitamos como un himno, sino que está hecha de razones vitales en el desarrollo de un pueblo. Un mapa de desconciertos diseñado con nuestra piel donde se amurallan las bocas que quieren tener voz propia. La poesía trata los sucesos en profundidad porque el creador oscila de manera única y particular en lo subterráneo de la complejidad humana. Es lo que han hecho los poetas colombianos que hoy conforman nuestra tradición más visible. Entre ellos hay autores que me resultan muy queridos $y$, por tanto, no puedo evitar mencionarlos: Luis Vidales integró la poesía a sus labores como político y estadista. Conviene releer sus obras La Obreriada y Suenan Timbres. Vidales supo de los cascos y su tortura, vivió exilios y persecuciones. Él sigue vigente porque la guerra de la que nos habló es la misma del júbilo inmortal. Vivía en San Diego, al costado norte del Cementerio Central en Bogotá. Recuerdo la época en que lo visitábamos con mayor frecuencia. Luego de enterrar a personajes cercanos, él nos esperaba. Dolido en su cama, siempre tuvo un adiós para las ausencias y las fuerzas que se apagaban poco a poco. Como las de él mismo.

Son varias las generaciones que llegamos a Juan Manuel Roca. En su obra encuentro un humanista que no hace concesiones. Al estar cerca a Juan Manuel, uno siente al hermano que dibuja un País Secreto, donde la fuerza de una orquídea puede detener el monumento de la desolación. En su poesía no hay un espejo convexo, está el 
mismo territorio en que todos nos bañamos. Es posible que luego de una conferencia, de una lectura de Juan Manuel Roca, algún extranjero se pregunte cómo en un país como el nuestro se logra pasar de la adolescencia a la adultez. Habrán preguntado, mirado el primer plano y tal vez no han encontrado indios con taparrabos pero sí algunos grupos de gentes que han querido callar la conciencia colectiva por medio de la barbarie.

La vida y obra de Matilde Espinosa ha sido reconocida y estudiada en algunos espacios, por eso, ella abre el telón de un escenario, donde se han reemplazado las linternas por visores nocturnos y los protagonistas cambian de nombre pero los objetos en movimiento y las naturalezas muertas son los mismos.

Matilde Espinosa vivió con indígenas, participó en los movimientos para lograr que las mujeres tuvieran derecho al voto, se atreve al divorcio. $Y$ en 1955 se ve afectada por los asesinatos en masa de campesinos en los Llanos, cuando ensartaban tres o cuatro personas, las montaban en los aviones y las arrojaban al vacío. A esta barbarie le llamaban la camándula. Los indios de Tierradentro eran tirados al Río Páez, amarrados en cadena. Estos hechos la movieron a expresar el horror a través de la poesía. A sus 45 años publica su primer libro Los ríos han crecido, título que le da nombre al siguiente poema:

\section{¡Los ríos han crecido!}

Su torrentera insomne

Desdibuja los rostros

De párpados abiertos,

En su delirio de piedras y raíces.

Crecen sobre las olas

Los cuerpos arrancados

Dela noche,

Sin luceros ni orillas,

Sin el aire caliente

Que hincharon las palabras, Las últimas palabras.
En su vientre, los ríos

Levantan cementerios

Y la muerte se cierra

En círculos morados

Que sacuden los peces

$Y$ devoran la sangre.

En cada espuma verde

Viajan los niños muertos,

Y en cada brazo de agua

Se preguntan las madres:

¿Dónde sus nidos tiernos?

¿Dónde su arteria rota

Clamorosa de arrullos?

En las gradas del alba

Van subiendo esqueletos

Con su carga madura

De grávidos espinos,

Y una afrenta de espigas

Que hace temblar la yerba.

¡Los ríos han crecido!

Un bosque humano lanza

Sus yemas al océano

Y las venas desatan

Palpitantes cordajes

Donde se estrella el viento

Y ensancha el corazón.

Volverán de los ríos,

Crecidos por la sangre

Y los hondos suspiros,

En madurez violenta

De secreta victoria

Para que sea más cierta

La pureza del agua.

Pero no es de estos poetas ya clásicos, de Vidales, Roca, Espinosa de los que quiero hablar. Quiero hacer una aproximación de las poéticas menos difundidas, que se refieren a las inmediatas cruces de la ignominia, en las cientos de masacres que han dejado torturados, desaparecidos, exiliados, muertos y desplazados, en los últimos veinte años en nuestro país. 
Hago una exploración del hecho poético como cosa que también nos representa, ya que el arte no oculta: es un estribo de las circunstancias, sus miradas son cartas testimoniales. Las diferentes poéticas nos permiten vernos como habitantes de un país con altos niveles de crueldad. Hacer memoria es volver a ver para no repetir. Porque otra de las consecuencias de la violencia (que se transforma en causa) termina siendo el silencio, cuando este nos lleva a la indiferencia; el silencio ni siquiera se esconde porque no tiene eco, está, existe en las pasividades y deambula por calles sin ningún rubor.

Un poeta no programa sus temas, por lo menos no es mi caso. Hago parte de un territorio, de una cotidianidad, entonces las vivencias se dan, llegan, me tocan y fundo un hecho artístico que, por supuesto, tiene la mediación de mi experiencia y mis pulsiones como ser dolido y agredido. En la visión del entorno y su relación con el mundo, el poeta rebota entre sus propias tensiones. El lector pone a prueba su identidad.

La historia ilustra la época, nosotros tratamos de plasmar el rostro de las almas, sin olvidar el llanto y las alegrías. Mi ojo no busca lo que quiere ver, yo encuentro el retablo para leer la explosión al otro lado de la burbuja. Puedo romper el reflejo del paisaje que cae en pedazos a mis manos, pero la escena sigue estática, acreditada, en la misma geografía en que me muevo. Es así cómo nuestra lectura de contexto, más que aleccionar, pone carne y concepto, piel y postura; donde las imágenes van más allá de la simple enumeración de acontecimientos.

Si la historiografía oficial impone (o lo intenta) asignar lo que debemos recordar y olvidar, el arte tendrá que ser de gran factura para alcanzar un lugar sobre la tierra y contribuir, quizás, a dar dignidad a las víctimas, que en últimas somos todos. Como dijo una señora luego de la masacre en el Salado -Bolívar- "Aquí nos mataron a todos". Tallulah Flores, poeta barranquillera consecuente a la contemporaneidad del horror, nos dice en su poema

\section{NOCTURNO}

Cuando se imponen las sombras

$Y$ se distrae el miedo bajo la indómita hierba

Se cierra una ventana

Para cada palabra que se pierde de vista

Descansando solemne entre piedras.

Enmudeció la noche

¿Qué haré si estoy viva? (1)

Creo que la memoria poética tiene un significado ético y político, la conquista de lo estético está en el resultado de la construcción a partir de lo real y lo imaginario. Y digo conquista de lo estético, porque el triunfo se lo lleva la infamia. Solo; nos atrevemos a transformarlo, a devolverlo en cosa artística para ser huella y propuesta. ¿Será posible la poesía como un ente reparador o, por lo menos, acompañador de las víctimas? También puede, por qué no, la misma culpa atrevernos a la palabra. El 17 de abril de 2010, a 20 años de la masacre en Trujillo, Valle del Cauca, un joven entregó a quienes peregrinaban por el río Cauca un escrito y ha sido una hermana dominica, actualmente amenazada, la que lo ha divulgado; ella escribe testimonio en verso y encontró que el texto del joven hace parte de la memoria escrita que se recupera en Trujillo.

\section{Al Río Cauca-Valle X Peregrinación Trujillo Abril 172010 ¿Quién eres Río Cauca?}

¿Por qué cuando estoy en las riveras me palpita Fuerte el corazón?

¿Por qué tiemblan mis manos cuando te toco?

¿Qué nada junto a los peces?

¿Qué corre por las aguas?

¿Qué se oculta bajo tus piedras y en tus oscuras grietas?

¿Acaso la tranquilidad de tu superficie es vacía?

Soy destino, pueblo hermano y soy testigo, soy humano como tú,

Porque en humano me han convertido, en mí 
hay carne, huesos, sangre, Lágrimas, odio y dolor, pero también hay amor, buenos recuerdos, soy igual a ti!

Junto a mis peces nadan almas, con mis aguas corre sangre y lágrimas,

$Y$ bajo mis piedras y entre mis grietas, se esconden oscuros secretos.

Mi superficie devela esperanza, una esperanza más allá del horror,

Más allá de la muerte y de la crueldad de los verdugos.

Encuentro en mí un descanso y un encuentro con el mismo Dios amado, Nos envía a todos a este mundo, a llorar y reír, a sufrir y gozar, A vivir y morir, sólo por Él, por su amor. Sí, pueblo hermano, fui testigo y hasta cómplice, Pero ahora soy suave y tranquila cuna.

Sin entrar a juzgar la elevación poética de este texto, puedo pensar que le asiste a su autor una necesidad de desahogo, de confesión, una forma de comienzo para su propia reparación. Cómo le serviría a este muchacho (nadie supo quién era) un acompañamiento en su escritura y por esta vía desocupar su cuerpo para volver a tener 15 años y empezar una adolescencia sana y diferente a la que le tocó vivir. Aquí, tiene sentido para mí la escritura, cuando me atrevo a poner en blanco y negro mi propia historia, la que me afecta y me permite el día siguiente.

Cuando se han vivido episodios terribles, en poblaciones donde sólo la herida ilumina el despojo, la poesía con rigor y vigor histórico, ayuda para la recuperación de la memoria. Una mujer decía que para ella "lo que habían vivido era como una película que se rebobina permanentemente", esa señora, no imagina lo que nos dijo en medio de su inocencia y dolor.

Cada quien se ubica en el ángulo de su comodidad y su postura ideológica, la que le permitirá abordar sus temas urgentes. El tono, las tensio- nes, tendrán las correspondencias con sus lectores, pero de no ser así, tampoco sería razonable pensar que no son válidas. Muchos que están en el ahora y adentro de Colombia sueñan con otros continentes, ajenos a las convulsiones, y solo les queda mascullar sobras que ruedan por la sangre.

No pido la categoría de salvadora para la poesía, tampoco es su expectativa; pero tengo la certeza de que si no hubiese leído realidad en presente a mis cinco años de edad, estos, hasta hoy, en la hipervivencia, no hubiesen valido la pena. Al leer poesía aprendo sobre la condición humana, reviso mi búsqueda y me reafirmo en ignorar el artilugio del acomodamiento.

En las dos últimas décadas nuestro país ha vivido las más tenebrosas manifestaciones de la violencia, pretendo develar cómo la poesía ha tenido una presencia esencial al mostrar las transformaciones del conflicto. Las imágenes por sí solas son poéticas, depende de quién las observe. Una mujer cubre su cabeza con los brazos y llora tumbada sobre lo poco que quedó con vida en su pueblo: un árbol. Hay una poética de la guerra, una poética no escrita, pero que documenta y afecta: en un lugar avasallado, queda una pared; en ella, un aviso, "La carnicería"; la cámara, que es la extensión del ojo del que la lleva, muestra cuerpos que empiezan a ser marcados con un número. Es una imagen repetida que muestra el escenario de una masacre. Pero, ¿Cuántos han considerado que allí había una venta de carne para el alimento y que ahora hay carne humana torturada y asesinada en el piso? ¿Y cómo el victimario se regodea con su actitud al dejar viva la pared para que se lea "La carnicería"? También ocurrió en la masacre de Trujillo, cuando dejaban en las puertas del cementerio los muertos, los que ya no cabían en las bocas del Río Cauca.

Hay poetas que han pulsado la palabra más allá de lo escrito, seres que han trabajado en lo comunitario, en lo pedagógico, en el periodismo. Isabel García Mayorca, poeta de Guamal, 
Magdalena, ha escrito libros de literatura infantil, es periodista y dicta talleres de creación para niños en la Localidad de San Cristóbal en el Distrito Capital:

\section{Volverán a cantar en noches de luna llena}

"Si su hijo es juicioso acuéstelo temprano, de lo contrario nosotros se lo acostaremos" A.U.C. (valla en la Costa Atlántica)

Antes los veía haciendo castillos en la arena. Improvisando dulces y vigorosas canciones. Poemas que también cantábamos al son de las estrellas y la luna llena en la remota infancia. Ahora sus voces cortadas deambulan entre el asombro y la desmemoria.

-Los niños de mi tierra no cesan de improvisar historias-

Algunos saltan puntuales a recordarnos que solo el amor les devolverá el canto de las mariposas en las del "Juio" y de la "Lleva".

Los niños de mi tierra volverán a cantar jugando a la "Nonima" en noches de luna llena.

"Juio", "Lleva", "Nonina", antiguos juegos de tradición oral de mi tierra. (2)

En abril de este año Isabel leyó el poema anterior en un centro cultural de Bogotá y para nuestro espasmo, los vigilantes de la entidad corrieron hasta ella y la abrazaron y le agradecieron por haberlos nombrado. La risa triste que me produjo este suceso me duró un mes, porque mientras yo montaba un evento, uno de estos señores me mostró el diseño de un águila en su cabello y le pregunté: ¿Por qué? Respondió que él había sido uno de ellos. No me entendió, yo quería saber por qué a mí me descubría el animal que tenía en su cabeza.

Los hijos que vendrán quizás encuentren una tierra menos ajada por el olvido, estos registros poéticos tal vez alcanzarán el reposo en nuevas generaciones. Los atisbos magistrales o cánones que clasifican tendrán la oportunidad de escindir o no las voces que han puesto en evidencia un momento histórico.

Beatriz Vanegas Athías es poeta, pedagoga y cronista. Desde sus primeros poemas y ensayos en los diarios de la realidad ha comunicado con su pluma firme, fuerte y valerosa. Ella descorre el velo y lo hace grafía.

\section{Rastro del horror}

4

Aquí estuvieron dos meses, con ellos compartieron desde el tinto aliviador hasta los hijos luminosos. Desde la noche culebrera hasta el amanecer sin sol y también la hamaca bondadosa.

Un día se fueron.

Una madrugada regresaron porque suponían que esa generosidad no era exclusiva para ellos.

La tarde del día que volvieron fue una tarde arrogante y el crepúsculo conejero ayudó a un mayor desamparo regando su esplendor púrpura sobre los matorrales. $Y$ no fue con bala. No lo merecían: La mona que un día quebró cimientos y edificó hogares, fue la encargada.

Entonces pasaron adelante acomodaron el rostro sobre la piedra: 
Una mano sostenía, otra asestaba.

Luego fueron los golpes secos de la mona: veintisiete exactos golpes

sobre la piedra que mató a Chengue. (3)

Desde que conozco a Beatriz, hace más de diez años, sé de sus preocupaciones. Ella canta desde la ternura, como solo alguien a quien le importa lo social puede hacerlo. En su poética hay ausencias, distancias, retornos inconclusos. Pero no olvidemos que los abandonos, los miedos y las fragilidades derivan de la guerra y sus consecuencias.

El texto poético simboliza hechos que registran la evolución de un ser humano, un pueblo y su relación con el territorio. Es la cosa estética que da voz al silencio de la desmemoria. El artista alcanza el centro de la tierra y su verdad.

$\mathrm{Y}$ hay quien mira adentro en una sentencia a manera de conclusión donde las palabras conjuran el polvo de los huesos. Ella es Ela Cuavas, licenciada en Español y Literatura de la Universidad de Córdoba, colaboradora de diversas publicaciones y gestora cultural.

\section{Carta para Arturo B. Deveriux}

Para John Carrillo

No des más vueltas a la rueda.

Estuvimos mucho tiempo

vagando por el bosque.

No nombrar fue nuestra esencia;

la metáfora es más engañosa que el sueño.

Fuimos sangre, fuimos espada.

Lo destruimos todo.

Ahora nos toca juntar los huesos. (4)

Vivimos un país con diversidad geográfica y poblacional. Habitantes somos y protagonistas, sin darnos cuenta de las músicas que ahogan el último miedo de las víctimas. Extraños, tan extraños somos que nos molesta confrontarnos para no tener que hacer el duelo. Las poéticas que ponen en evidencia la otra cara de la historia no son atractivas y se cubren con cientos de tratados donde la competencia de la palabra creativa está fuera del orden normativo.

Los procuradores del conflicto han cambiado sus nombres y todo es dispersión, juego macabro, sin ninguna lógica. El cóndor mutó en águila y se apropió de la nación. Desde la sabana hasta la más alta cordillera, sabe encontrar las presas para beberse la última gota de agua en la sed de sus habitantes.

El poeta recoge partituras del suelo y las lleva al papel, mientras se pregunta si los resultados de su palabra son casualidades, causalidades, o gritos de la tierra difíciles de ignorar.

Yirama Castaño, de Socorro, Santander, participa en la creación de proyectos literarios escritos, apoya la formación y difusión del arte y en algunos ensayos ha sustentado la necesidad de la poesía. Se cubre con el aleteo de mariposas para evitar el temblor de sus amuletos. Ajena a las algarabías hace que su silencio se escuche para decirnos:

Rumor del Valle

Para Karin Kuhfeldt

Cuando comencé a viajar, no pude resistir la tentación de parar en la estación equivocada.

Pequeño pueblo de bombilla en la escalera, habitar cualquiera de tus casas era bailar en una ronda de gaitas y tambores.

No importaba la lengua arenosa, ni el calor colándose en la pared de la cocina. Bastaban eso sí los olores de la tierra, la lentitud descalza en el centro de la plaza. Nadie tenía nombre y sin embargo todos se llamaban.

Las mujeres pintaban sus labios en punto de las seis y los hombres aplastaban fichas en medio de los gritos y la fiesta. Pero un día llegaron los falsos monjes 


a pintar con aerosoles
agujeros negros en tu cielo.
Pequeño pueblo,
ahora que vuelvo con el camino despejado,
ahora que la brújula señala el norte sin
equívoco
hay algo que no entiendo,
todos callan
y una fila de cantadoras
con velas en las manos
alumbran la marcha
que aleja a los niños
de la prometida tierra (5)

El lenguaje de Yirama es certero, construye la imagen de manera delicada, no por miedo de entrar a la noche, sino porque sabe que todos los seres humanos merecen un tanto de bondad, y con mayor razón los equivocados.

En un pueblo arrasado por la incursión paramilitar le preguntaron a un hombre si a él lo había tocado el conflicto y respondió: "hasta ahora no, pero quién sabe" ¿Hasta dónde este señor contextualiza su propia realidad? La guerra trae consigo cientos de hechos vinculantes que algunos no sabemos leer. Inclusive la naturaleza se enoja y lava la sangre que aún se mueve en las hojas de las árboles y entonces los ríos se levantan, se desentierran las fosas comunes y muchas madres se quedan sin saber en dónde están sus hijos desaparecidos. Las organizaciones de Derechos Humanos les ayudan a reclamar y así aprender a gritar "vivos se los llevaron, vivos los queremos"y ¿Qué pasa?... Nada... Porque hay desconfianza con algunas organizaciones nacionales e internacionales que no siempre manejan con honestidad los recursos. Es decir, la guerra también deja una empresa, que podría calificarse como fábrica de víctimas con patrimonio propio y razón social de hecho. Quienes nos encontramos con estas manifestaciones y el coro de las familias de los desaparecidos, pasamos de largo, pues sus rostros se nos vuelven parte del museo trashumante del horror.
Las artes responden a su tiempo, descubren las pezuñas de las aves y muestran su vuelo. La guerra vuelve el entorno pesado y algunos no sabemos cómo canalizar la violencia, se nos sale la mezquindad y despreciamos sin ningún sonrojo. El otro día, en la EPS, una anciana le decía a la terapeuta que el ortopedista le había dicho que si cada vez cojeaba más, lo mejor sería que caminara empinada. La joven especialista sonrío y yo no me atreví a decirle que era imposible empinarse con artrosis, cuando se lleva tres partes del siglo con la guerra en la cadera derecha.

Considero que hay hechos fundamentales en el recuerdo individual que son originadas en una sociedad. Si la poesía construye esa memoria tendrá alguna utilidad, ya que la historia habla de lo ocurrido, pero lo memorable para los procesos sociales no son los compendios técnicos sino el cómo se recuerda. Es necesario contrastar las poéticas con la realidad para encontrar el lugar del arte en los ejercicios de reparación. La memoria desde el adentro, que señala con el dedo roto su relación con el alma, que involucra la crítica y diversos puntos de vista, incluidos los de la oposición. Es decir, muchos motivos para sustentar un debate.

Solo nosotros, protagonistas activos o pasivos, determinamos desde lo individual las identidades colectivas como suerte de una memoria. Es en el acumular acontecimientos significativos y comunes que hacemos un pueblo con historia. La poética tiene una lupa que se acerca al contexto, a relatos subterráneos. La poesía da una nueva voz a la narración histórica, recrea tiempos y espacios donde todo es sustancial porque se recibe en el cuerpo, en los sentidos.

Es tanto el daño que hace la guerra a una sociedad que se afecta hasta el lenguaje. En Colombia no advertimos eso, entonces es fácil encontrarnos con posturas muy curiosas. Un día llamé a una entidad que hace promoción de lectura, pregunté por alguien y me dijeron que ella se encontraba en acuartelamiento de primer grado, porque estaban organizando los 
componentes de las bibliotecas. Hace pocos días al indagar por el estado de mi trámite para pensión me respondieron que estaba en Proceso de imputación. Luego del impacto le pregunté a la señorita que me atendía si eso quería decir que estaban revisando y me dijo que sí, que estaban cotejando las semanas con los registros existentes. La lista es larga. Cuando se organizan los planes de acción en las entidades a uno le dicen que hable de los programas emergentes. Así podría entregar muchos ejemplos de cómo la guerra penetra en lo cotidiano de las personas y los procedimientos. Esta ambigüedad de lenguaje puede ser peligrosa.

La poeta Lilia Gutiérrez de Macaravita, Santander, es química y bióloga, campos en los que se ha distinguido por sus investigaciones y libros de texto. Mereció el primer premio en el concurso mundial de Ecopoesía y es embajadora del Círculo Universal de paz con sede en París y Ginebra. En su libro Pasos alquilados encontramos este poema.

Insilio

Regresar

con la firme alegría

de hallar la sonrisa

y el encuentro del barrio.

El primer día de emociones

y luego, las siguientes miradas

te enseñan los espacios

y los tiempos ya ocupados

El festejo

el único festejo

lo tienes en familia

en los recuerdos de la casa

Aunque intentes caminar

las mismas calles y los mismos parques

tu figura delgada y los pasos alquilados

delatan tus gestos recién coleccionados.

El tiempo te ha separado de la vida y

del afecto.

Cuando se inicia el exilio la desvanecida

Iluvia borra el puerto de partida. (6)
Lilia, que estudió Química Nuclear en Hamburgo, Alemania Federal, cuando aún existía el muro, sabe de los retornos y también de quienes en el exilio ven cómo las fronteras cercan los sueños.

Los artistas no han escatimado esfuerzos para hacer oposición a la guerra. Los poetas Fernando Rendón y Gabriel Jaime Castro crearon el Festival de Poesía de Medellín. Se aprovecha esa tradición poética que existe en Antioquia, una región de gentes que saben de memoria los poemas clásicos, hasta los asesinos, después de alabar el nombre de su Dios, recitan y ponen de modelo versos, obras y poetas. Este festival ha logrado una mirada distinta a nuestro país, allí se congregan miles de personas en un ritual con la música de la palabra. Las obras poéticas de Fernando y de Gabriel también dan cuenta de días aciagos y siguen en la apuesta por exorcizarlos.

En Trujillo, un día se llevaron la partera, quien fue torturada y luego cortada en pedazos y lanzada al río Cauca. ¡Llevarse a la partera de la Vereda la Sonora! ¿Acaso no es desaparecer a la persona que recibe la vida? Los testigos presenciales de las masacres en Trujillo han sido declarados locos, las madres que quedaron vivas murieron de pena moral, situaciones que se abren para muchos interrogantes. Pero la poesía no puede responder, apenas es un registro de lo que nos pasa.

No es casualidad que en las masacres ocurridas en el departamento del Meta los cuerpos sean abandonados en el matadero municipal, es que los asesinos no tenían que hacer un trabajo de campo para precisar las locaciones. El victimario acierta porque su mano huele los lugares perfectos para el crimen.

Pero el baile de la oscuridad ocurre en cualquier parte, con o sin música, con danza o sin danza, y sobre el cuerpo que se corta en pedazos, estando vivo, aún hay mucho que decir. Esa memoria no se ha escrito. 
Quiero mostrar un poema de Fernando Vargas Valencia, quien logró cierto efecto al apropiarse de las entrañas de una mujer para decirnos:

\section{EL SALADO I}

"Los paramilitares que hace nueve años participaron en la masacre ocurrida en El Salado (Bolívar) obligaron a varias mujeres a desnudarse y bailar delante de sus esposos o padres, que después fueron asesinados". Periódico El Tiempo.

La vergüenza de bailar

ante tantas miradas.

La vergüenza de mi piel desnuda

cuarteada por las sombras

de las aves tuertas.

El miedo que eriza mis senos

y que me hace temblar.

No puedo bailar así,

no con este olor a pólvora

y a muerte pospuesta.

Sé que voy a morir

y no quiero hacerlo bailando.

Mi madre me enseñó la danza

como juego de cortejos.

Nunca me habló de esta preñez fúnebre,

de esta sensación de terrible soledad sin

música.

Este ejército de hombres

va a arrojar la rabia en cualquier momento.

No puedo, no quiero bailar

si la música es un golpe de luz

en la boca abierta de la noche.

Las ráfagas prometen venir pronto

y me parece demasiado impuro

recibirlas danzando.

No, no quiero bailar desnuda

si mi padre me observa. (7)

Este poema aparece en el libro Épica de los Desheredados de Fernando Vargas Valencia, poeta de Bogotá, nacido en 1984 que se desempeña como auxiliar de la cátedra de Sociología Jurídica. El autor como jurista ha escuchado testimonios, y con la introducción de lo plano de la noticia concibe su creación.

Vivo en el asombro, hay diferentes visiones en el registro sobre las memorias de las violencias, diálogos invisibles. Poco se sabe de los esfuerzos encaminados a que la palabra poética sirva para dar un poco de dignidad a las víctimas que seguimos siendo todos. Aunque el canto de los pájaros cambie de nombre, anuncia el mismo terror.

Andrea Cote Botero, poeta de Barrancabermeja, se graduó en Literatura y adelanta estudios de PHD en Lenguas Romances en la Universidad de Pennsylvania. Ha publicado varios libros de poesía y en su tierra natal, durante varios años, organizó un festival de poesía. Esta joven poeta me permite cerrar estas líneas porque yo también "temo":

\section{Temo}

Temo que el infierno sea tan largo como el silencio de Dios,

que su tiempo esté habitado por el frío de los templos.

Temo que el silencio sea silencio afuera de la muerte,

que luego del tiempo aún conservemos la memoria.

Temo no dormir tampoco en ese sueño eterno y que hasta allí nos siga la desesperación de los relojes. (8)

\section{Biografías:}

\section{Matilde Espinosa}

Nació el 25 de mayo de 1910 en Huila, Departamento del Cauca. Falleció, a los 97 años de edad, el 19 de marzo de 2008. Publicó los libros de poemas: Los ríos han crecido (1955), Por todos los silencios (1958), Afuera las estrellas (1961), Pasa el viento (1970), El mundo es una calle larga (1976), La poesía de Matilde Espinosa (selección, 1980), Memoria del viento (1987), Estación desconocida (1990), Los héroes perdidos (1994), Señales en la Sombra (1996), La sombra en el muro (1997) y La tierra oscura (2003). Ha sido incluida en varias antologías y estudios críticos sobre poesía colombiana y latinoamericana. Siendo apenas una adolescente, en 1929, contrajo matrimonio con el famo- 
so pintor payanés Efraín Martínez, con quien vivió varios años en París y tuvo dos hijos. Viajó por Europa y vivió en París, Madrid y en países que pertenecieron a la esfera socialista. Ha sido traducida al francés y al inglés. Recibió varios premios y condecoraciones por su trabajo literario.

\section{Tallulah Flores}

Nació en Barranquilla. Estudió Lingüística en la Universidad Popular de Bucarest, Rumania, obtuvo el título de Educación de la Universidad Javeriana, y de Especialista en Pedagogía de la Lengua en la Universidad del Bosque de Bogotá. Ha sido docente de básica secundaria y universitarios. Ha publicado los libros de poesía: Poesía para armar, Voces del tiempo y Cinematográfica. Ha participado en encuentros internacionales de poesía.

\section{Isabel García-Mayorca}

Nació en Guamal, Magdalena. Estudió Periodismo y Pedagogía. Se ha desempeñado como profesora de colegios y actualmente orienta talleres de creatividad para niños. Ha publicado en varias revistas. Finalista en el año 2000 del concurso de poemas convocado por el Museo Rayo. Fue una de las ganadoras del concurso Contrababel de los oficios, convocado por la Casa de Poesía Silva en el 2007. Ha publicado su libro de poemas Todo Abril y lo que va de Mayo.

\section{Beatriz Vanegas Athías}

Nació en Majagual, Sucre, Colombia, en 1970. Poeta y cronista. Ganó el Premio Nacional de Poesía Universidad Externado de Colombia en 1993, con el libro Abriendo las piernas a la carne. Obtuvo el Premio Departamental de Poesía, Fondo Mixto de Sucre, con Galería de perdedores. En 2010 ganó el Premio Internacional de Poesía Pilar Paz Pasamar de Jerez, España y en 2012 el Premio Nacional de Poesía Casa Silva, "La Poesía de los Objetos". Se desempeñó como cronista y columnista de los suplementos culturales en los diarios Vanguardia Liberal, El Meridiano de Sucre y Córdoba. Trabajos poéticos suyos han sido publicados en antologías de poesía departamental y nacional y en revistas impresas y digitales. En 2006 publicó el libro de poemas Los lugares comunes (Editorial Sic, de Bucaramanga). Con tres heridas yo (Editorial Caza de Poesía, 2012), De la A a la Z Colombia (Editorial Everest, León, España 2012, poemario infantil), Crónicas para apagar la oscuridad (Editorial UIS, 2011, crónicas)

\section{Ela Cuavas}

Montería, Córdoba, 1979. Licenciada en Español y Literatura de la Universidad de Córdoba. Ha sido colaboradora en diversas publicaciones impresas y digitales, entre ellas El Meridiano de Córdoba. Como gestora cultural ha intervenido en organización de proyectos literarios y audiovi- suales. En la actualidad es docente de lengua española.

\section{Yirama Castaño}

Nació en Socorro, Santander. Periodista y editora, ha publicado los libros: Naufragio de luna (1990), Jardín de sombras (1994), El sueño de la otra (1997) y Memoria de aprendiz. Participó en la creación de la Fundación Común Presencia. Sus poemas han sido traducidos y publicados en numerosos medios de Colombia y el exterior.

\section{Lilia Gutiérrez Riveros}

Nació en Macaravita, Santander. Química y bióloga, campo en el que se ha distinguido por sus investigaciones y numerosas publicaciones. Ha cultivado su talento literario, en poesía, ensayo y cuento. Libros de poesía: Con las del tiempo, (1985); Carta para Nora Böring y otros poemas (1994); La cuarta hoja del trébol (1997); Intervalos (2005); Pasos alquilados (2011). Algunos poemas han sido traducidos al inglés, al francés, al portugués, al alemán, al italiano y al chino. Incluida en antologías y estudios críticos. Embajadora de la Paz del Círculo Universal de Embajadores de la Paz con sede en París y Ginebra. Merecedora del premio del I Concurso Mundial de Ecopoesía 2010.

\section{Fernando Vargas Valencia}

Nació en Bogotá, en 1984. Abogado de la Universidad Externado de Colombia. Auxiliar de investigación en sociología jurídica en el Instituto de Estudios Interdisciplinarios de dicha universidad. Estudios en Literatura y Sociología. Tutor de la Unidad de Extensión de la Corporación Internacional para el Desarrollo Educativo, en programas de formación docente en el área de Cultura de la palabra y creación literaria. Ganador de varios concursos. Director de la revista poética Fata Morgana. Coordinador de la sección literaria de la Revista Cultural Somos - Libertad Bajo Palabra, de la Universidad Externado de Colombia. Incluido en varias antologías de nueva poesía hispanoamericana en Perú, España y Cuba. Invitado a varios encuentros nacionales e internacionales de poesía en Colombia, Brasil y México.

\section{Andrea Cote Botero}

Nació en Barrancabermeja, 1981. Estudió la carrera de literatura. Publicaciones: Puerto Calcinado (2003), por el que ha recibido el Premio nacional de Poesía Universidad Externado de Colombia y el Premio Internacional de poesía joven Puentes de Struga (2005); Una fotógrafa al desnudo, Biografía de Tina Modotti (2005). Blanca Varela o la escritura de la soledad (Ensayo, 2004); Cosas frágiles (selección del libro inédito A las cosas que odié, que apareció publicado en Transmutaciones, España, 2010). Formó parte del comité organizador del Festival Internacional de Poesía de Medellín. Actualmente adelanta estudios de 
PhD en Lenguas Romances en la Universidad de Pennsylvania.

\section{Referencias Bibliográficas}

Flores, T. (2008) Voces del tiempo y otros poemas, p.35. Colección Un libro por centavos No.40, Universidad Externado de Colombia Septiembre: Bogotá

García-Mayorca, I. (2010) Todo abril y lo que va de mayo, p.26. Ediciones San Librario: Bogotá.

Vanegas Athias, B. (2006) Los lugares comunes. p. 53. Editorial Proyectos culturales de sistemas y computadores: Bucaramanga.
Cuavas, E. (2011) Juntar huesos.. Ediciones Pluma de Mompox: Bogotá

Espinosa, M. (1955) Los Ríos han crecido

Gutiérrez Riveros. L. (2011) Pasos Alquilados. Caza de libros: Ibagué.

Vargas Valencia, F. Épica de los desheredados. Colección Isla negra:

Cote Botero, A. (2003) Puerto Calcinado. Colección Un libro por centavos, Universidad Externado de Colombia: Bogotá 